\title{
LA COMUNICACIÓN DEL PERSONAL DE ENFERMERÍA CON EL EQUIPO QUIRÚRGICO
}

\author{
Ana Laura Muciño Carrera ${ }^{1}$, Danelia Gómez Torres², Guadalupe Sánchez Arias³, Elizabeth Bernardino ${ }^{4}$, \\ Solange Meira de Sousa ${ }^{5}$
}

\begin{abstract}
RESUMO: El objetivo de esta investigación fue interpretar la comunicación de la enfermera con el equipo quirúrgico. Estudio cualitativo, se empleó la Etnometodología, sustentada en la Teoría de comunicación humana de Watzlawick, las participantes del estudio fueron 19 enfermeras, durante la recolección de datos se aplicaron guías de entrevista y observación de febrero a mayo 2015, el estudio se realizó en un hospital de tercer nivel en México. Se analizó con el método de análisis de contenido, para su discusión, la teoría antes señalada. La enfermera lleva a cabo la comunicación con previsión, confirma la información más significativa, señala la importancia de garantizar la seguridad del paciente al comunicarse. Concluyendo que el profesional de Enfermería propicia la comunicación asertiva dentro del equipo; no obstante, se requiere participación activa de todos, para obtener reciprocidad y sintonía en la información, así sustentar una comunicación efectiva que evite riesgos durante los procedimientos quirúrgicos.
\end{abstract}

DESCRITORES: Comunicación; Enfermeros; Quirófanos.

\section{NURSING STAFF COMMMUNICATION WITH THE SURGICAL TEAM}

ABSTRACT: The objective of this qualitative study was to interpret the communication between nurses and the surgical team. Using the Ethnomethodology (based on the Human Communication Theory of Watzlawick), this study, which was conducted in a third-level hospital in Mexico, included 19 nurses. During data collection, interview and observation guides were applied from February to May, 2015. For the discussion, the theory discussed above was analyzed with the content analysis method. The nurses anticipate communication, confirm the most significant information, and point out the importance of ensuring patient safety when communicating. Concluding, nursing professionals encourage assertive communication within the team; nevertheless, this requires the active participation of all team members in order to obtain information with reciprocity and harmony, thus keeping an effective communication that avoids risks during surgical procedures.

DESCRIPTORS: Communication; Nurses; Operating Rooms.

\section{A COMUNICAÇÃO DO PESSOAL DE ENFERMARIA COM A EQUIPE CIRÚRGICA}

RESUMEN: O objetivo desta pesquisa foi interpretar a comunicação de enfermeiras com a equipe cirúrgica. Estudo qualitativo, em que se utilizou a Etnometodologia, com base na teoria da comunicação humana de Watzlawick. As participantes do estudo foram 19 enfermeiras, durante a coleta de dados foram aplicados formulários de entrevista e observação, de fevereiro a maio de 2015, e o estudo foi realizado em uma hospital terciário do México. A teoria acima mencionada foi analisada com o método de análise de conteúdo, para sua discussão. As enfermeiras realizam a comunicação com previsão, confirmam a informação mais significativa, e observam a importância de garantir a segurança do paciente ao se comunicar. Conclui-se que o profissional de enfermagem promove comunicação assertiva dentro da equipe; no entanto, requer-se a participação ativa de todos para obter reciprocidade e sintonia na informação, e assim manter uma comunicação eficaz para evitar riscos durante os procedimentos cirúrgicos.

DESCRIPTORES: Comunicação; Enfermeiros; Salas Cirúrgicas.

${ }^{1}$ Enfermera. Maestra en Enfermería Quirúrgica. Facultad de Enfermería y Obstetricia de la Universidad Autónoma del Estado de México. Toluca, Estado de México.

${ }^{2}$ Enfermera. Doctora en Enfermería. Profesora investigadora de la Facultad de Enfermería y Obstetricia de la Universidad Autónoma del Estado de México. Toluca, Estado de México.

${ }^{3}$ Maestra en Administración de Sistemas de Salud, Facultad de Enfermería y Obstetricia de la Universidad Autónoma del

Estado de México. Toluca, Estado de México.

${ }^{4}$ Enfermera. Doctora en Enfermería. Profesora de la Universidade Federal do Paraná. Curitiba, PR, Brasil.

${ }^{5}$ Enfermera. Estudiante de Doctorado en Enfermería. Universidade Federal do Paraná. Curitiba, PR, Brasil. 


\section{INTRODUCCIÓN}

La comunicación es la acción y efecto de compartir, trasmitir ideas, mensajes o sentimientos a nuestros pares, con el propósito de llegar a acuerdos, establecer metas, cumplir con los objetivos en cualquier ámbito, a través de palabras, o mediante el envío y recepción de mensajes sin éstas (no verbal)

(1). En el área de salud, específicamente en el área quirúrgica, actualmente los problemas se presentan por una deficiente comunicación; sin embargo, los estudios previos relacionados con la temática, no informan acerca de la interacción del personal de enfermería con los miembros del equipo quirúrgico.

Estudios de caracterización de patrones en la comunicación de las salas de cirugía mencionan las fallas de esta acción entre el equipo quirúrgico, los cuales impactan en la seguridad del paciente, pues han revelado que existe una comunicación deficiente entre los profesionales del equipo quirúrgico, adjudicando a esta condición, el incremento en la morbimortalidad del paciente. Este es el caso del profesional de enfermería, quien percibe la comunicación dentro del equipo interdisciplinario como insuficiente e ineficaz; estudios relacionados con esta actividad no aportan la causa de este hecho, por esta razón se llevó a cabo la presente investigación.

Las investigaciones sobre la teoría de la comunicación adoptan un enfoque sistémico, posee algunas propiedades de naturaleza axiomática que encierran consecuencias interpersonales básicas. Watzlawick ${ }^{(2)}$ y colaboradores las definen en cinco axiomas presentes en toda interacción humana; es decir, una persona no puede dejar de comunicarse porque cualquier comportamiento trasmite un mensaje. El segundo axioma tiene relación respecto a lo que se dice y la relación que existe entre los comunicantes para que se dé una interpretación del mensaje, el tercer axioma hace referencia a lo múltiples intercambios en cualquier conversación, por ejemplo la acción y el efecto de los mensajes.

Uno de los últimos axiomas analiza la comunicación verbal y la comunicación no verbal, pues ambas se complementan e influyen directamente en la interpretación del mensaje entre quienes interactúan. Y para concluir también en una conversación existen las relaciones que se dan entre los comunicantes que desempeñan el mismo rol o bien, donde las relaciones son distantes entre los hablantes ${ }^{(2)}$.

La comunicación humana comprende tres áreas, particularmente la pragmática, que se refiere a sus efectos sobre la conducta, es decir, estos dos términos (comunicación y conducta) son percibidos como sinónimos, pues los elementos de la pragmática no son sólo palabras, si no también signos relacionados con la comunicación no verbal. Además, las conductas personales tienen componentes esenciales en el contexto donde la comunicación tiene lugar. Por ende, desde la pragmática, toda conducta, no sólo el habla es comunicación, por tanto, afecta a la conducta, de ahí que la pragmática se interese particularmente en la relación emisor-receptor que ocurre en cualquier interacción ${ }^{(1-2)}$.

El objeto de estudio es la comunicación de la enfermera con el equipo quirúrgico, caracterizado como un grupo que vive unido, y que a su vez, construye un orden social establecido también por el razonamiento lógico. El estudio se realizó con el objetivo de interpretar el comunicar de la enfermera con otros profesionales y señalar la interacción del equipo quirúrgico de una institución hospitalaria de tercer nivel, o sea un hospital de grande porte en México.

\section{Metodología}

Es una investigación de enfoque cualitativo, cuyo objetivo fue comprender la perspectiva de los participantes respecto a los fenómenos que les rodean, así como profundizar en sus experiencias, perspectivas, opiniones y significados. Se empleó como método la Etnometodología que analiza las actividades cotidianas (métodos de los miembros para hacerlas visiblemente racionales y comunicables) Ilevadas a cabo para efectos prácticos, explicables, en toda organización ${ }^{(1)}$. Se sustentó con la Teoría de la Comunicación Humana de Paul Watzlawick ${ }^{(1)}$ quien aborda el aspecto pragmático; además se centra en las propiedades básicas e interpersonales, axiomas de la comunicación.

El escenario de estudio fue en las salas quirúrgicas de un hospital de tercer nivel en México. Los actores sociales fueron los profesionales de enfermería del área quirúrgica que integraban el equipo quirúrgico (enfermeras, médico cirujano, anestesiólogo, así como sus respectivos residentes). Son 19 
profesionales de enfermería que laboran en el turno diurno en matutino y vespertino en dicha área. Se incluyó a quienes dialogaron activamente y participan durante los procedimientos quirúrgicos, fungiendo como circulante o instrumentista, con más de 6 meses de permanencia en las salas, siendo esto los criterios de participación; se eliminó una entrevista y cinco observaciones que no aportaron datos relevantes al objeto de estudio.

La recolección de datos se realizó en un periodo de ocho semanas de febrero a mayo 2015, en la primera etapa se llevó a cabo el reconocimiento del escenario de estudio y de los participantes, en seguida, una observación pasiva realizada durante los actos quirúrgicos, durante tres días con una duración de entre tres a cuatro horas en promedio por día para conocer el escenario, posteriormente se efectuó la recolección de datos por aproximadamente 250 horas, utilizando una guía de observación de 15 aspectos, que fue aplicada en tiempo real durante la realización de los actos quirúrgicos.

Todos los procedimientos fueron observados desde el ingreso del paciente a la sala quirúrgica hasta su egreso de la misma, en el cual se abordan los aspectos de los comunicantes, las características de los mensajes que se trasmiten y a quienes se dirigen.

Otra de las técnicas fue la entrevista que se desarrolló mediante una guía semi-estructurada, establecida a partir de las preguntas conductoras; como fue la opinión y diferencias al comunicarse con cada uno de los miembros del equipo, relevancias, perturbaciones y acciones que detecta el profesional de enfermería en la comunicación. Se realizaron 19 entrevistas a enfermeras observadas en el turno de trabajo fueron 10 del turno matutino y 9 del turno vespertino (con éste número se obtuvo la saturación de datos). Cada entrevista se grabó con un equipo de audio, previa autorización y consentimiento firmado por las participantes para dar cumplimiento a los aspectos éticos marcados en la ley general de salud mexicana, en materia de investigación para la salud, según el artículo 14 fracción V.

Para el tratamiento de los datos, se transcribieron las entrevistas y los registros de las guías de observación en un procesador de textos Microsoft Word, una vez capturados, y para guardar el anonimato de los participantes, se les asignó un número del 1 al 19, empleando el análisis de contenido para la segmentación de los datos en unidades significativas, se identificó, clasificó y codificó la información con técnica cromática para resaltar la relevancia de cada etiqueta, facilitando la asignación de pre categorías, posteriormente fueron discutidas las ideas más repetidas, agrupándose en elementos que las tradujeron de forma sintética para la agrupación en categorías ${ }^{(3)}$.

Los resultados se presentaron en categorías discutiéndose de acuerdo con la Teoría de Paul Watzlawick ${ }^{(1)}$. Para dar cumplimiento a la ley en materia de investigación como lo marca la ley general en salud mexicana en su artículo 100, la cual señala que se guardara el anonimato, por ello se marcó con un número a cada participante, en el mismo tenor, el comité de ética del Centro Médico Adolfo López Mateos, según número 217B50061/4848, fue quien aprobó el proyecto de investigación, el cual fue instrumentado de marzo a abril de 2015.

\section{RESULTADOS}

Los participantes en la investigación que fueron observados en 20 actos quirú rgicos, estuvo integrado por 19 enfermeras especialistas todas de género femenino, 21 médicos de diferentes especialidades de cirugía y 16 especialistas en anestesiología, además de 23 residentes de medicina. Todos con al características básica de estar ligados formalmente a la institución de salud.

El quirófano es un área donde los mensajes deben ser manifestados de forma clara y precisa con el fin de garantizar la seguridad del paciente, por esta razón, es fundamental, entre quienes conforman el equipo, entenderlos debidamente, a fin de lograr una mayor eficiencia durante los procedimientos. Así lo manifiesta una participante:

Tú le dices al cirujano! Sabes qué!, falta una gasa [...], en ese asunto sí enfatizas, me hace falta una gasa o una aguja o una pinza, independientemente y si hace caso omiso, le dices a la compañera circulante-, se le comentó al médico e hizo caso omiso [...] a mí no me importa que esté de malas, ¿Sabes qué? Me hace falta tal cosa. (E-5) 
Lo anterior permite inferir la nula escucha del receptor, ocasionando fallas en el proceso de comunicación relacionado con la oposición al contenido del mensaje. La falta de acuerdos en el intercambio de éstos causa conflictos en las relaciones, los cuales surgen cuando uno de los comunicantes no realiza la función emisor-receptor o su conducta inapropiada afecta directamente al otro; se hace caso omiso de la petición del profesional de enfermería; la falta de reciprocidad en la información dificulta establecer una comunicación efectiva, lo que repercutirá directamente en la atención del paciente.

De lo contrario, la repetición de mensajes emitidos a su equipo quirúrgico, generan una comunicación deficiente que puede dar lugar a complicaciones durante el procedimiento:

Si se necesita una sutura vascular y desde un inicio le dices al médico que no hay, y cuando va a utilizarla él dice: ipásame el pro lene! [Sutura vascular], contesto: le avisé que no la tengo-, [...] siempre que ingresa el paciente, hago hincapié, falta esto, le recuerdo esto. (E-10)

En consecuencia, para impulsar una comunicación efectiva, se debe hacer énfasis en las acciones que promueven beneficios para todos los participantes del equipo quirúrgico y esencialmente para el usuario de los servicios de salud; así, el profesional de enfermería es quien debe enfocar sus acciones a fin de prevenir posibles retrasos y fallas en la cirugía, por esta razón, dicha información debe transmitirse al equipo quirúrgico. Una entrevistadas lo manifiesta así:

Al faltar equipo para la cirugía, comunicarlo al cirujano, al médico anestesiólogo y enfermera tiene que saber [...] ¡Sabe qué! [Anestesiólogo] en la central de equipos y esterilización no se encuentra el material del paciente, no vaya a dar la anestesia, iespere!,- permítame preguntar-, de igual manera informar al cirujano que el equipo necesario para la cirugía del paciente no se encuentra en central de equipos y esterilización, eso es indispensable. ( $E$-11)

Los profesionales de la salud deben usar frases confirmatorias para hacer válidas sus funciones, vigilando el desarrollo del procedimiento y corroborando la información para mejorar las directrices de seguridad; al mismo tiempo, identifica al paciente y, verifica el sitio correcto de la cirugía por realizar; así lo refleja lo señalado a continuación:

Debe existir comunicación para todo, para informarle al cirujano, todos deben saber y si tengo alguna duda, cuando es de trauma, ¿la fractura es tibia izquierda o derecha?, para corroborar esa información, debe ser comunicado [...] así sea un detalle mínimo y tú como enfermera informarlo. (E-8)

La exclusión de uno de los miembros del equipo, al momento de transmitir información, es causa de errores en la comunicación; ante esto, el profesional de enfermería se percibe así mismo como el más vulnerable ante los eventos adversos que se presenten durante el procedimiento por esta causa:

Enfermería siempre va al frente, el paciente se complica ¿por qué?, porque el médico anestesiólogo no me informó; el paciente fallece, y nunca te enteraste a qué hora inicio la anestesia general, cuándo lo ventiló. $(E-3)$

Para que exista reciprocidad en la comunicación, se deben emplear correctamente los medios con que se cuenta, uno de los más característicos es la voz, considerada una herramienta para el desarrollo de la habilidad oral, además, la personalidad está relacionada con ésta, de ahí que el tono que se utiliza al hablar determina si el mensaje es entendido debidamente, lo cual da credibilidad al comunicador. Al utilizar un volumen adecuado en el tono de voz se evita el desconcierto entre los comunicantes:

A veces no hablamos claro y fuerte, eso es causa de confusión [...] eso es lo que falta, que nos hablen claro, preciso y fuerte, porque al utilizar un volumen bajo, no nos entendemos bien. (E-4)

Una persona, al dirigirse a otros, debe modular el volumen de su voz para dar diversos matices que aumenten su expresividad y validen su mensaje ante los demás:

Si es relacionado con el paciente, lo puedo decir en voz alta [... ], la persona a la que me dirijo me tiene que responder, si no me responde, pues lo repito. (E-17)

Además de los aspectos mencionados, las emociones interfieren en el proceso de la comunicación y tienen gran influencia en las interacciones cotidianas, afectando la armonía de los profesionales y por lo tanto el clima laboral del equipo quirúrgico. 
Si llego enojada por alguna situación, ya es un sentimiento que traigo, y me habla alguien y aun que yo no quiera le contesto mal, entonces va a decir la otra persona, no le voy a preguntar nada, porque me va a contestar. $(E-8)$

En muchas circunstancias depende de la relación emocional que tengan los que interactúan y el contexto en el que se desarrolle su conversación.

\section{- DISCUSIÓN}

La dinámica de la comunicación es transaccional, a través del intercambio de mensajes, la responsabilidad que adquieren los comunicantes es compartida. Saber escuchar, logra que los interlocutores se sientan comprendidos al ser atendida su intervención, incrementando su autonomía, flexibilidad y éxito al interactuar.

Asimismo, la buena comunicación - entendida desde la escucha activa, la empatía y la autenticidaden la transmisión de mensajes y solución de problemas, aplicada correctamente, hace más inteligible la vida laboral de los profesionales ${ }^{(4)}$ en consecuencia, el personal de enfermería promueve la escucha activa para lograr un entendimiento eficaz y satisfactorio dentro del equipo quirúrgico. Esta acción consiste en asimilar la información esencial para comunicarla de forma oportuna durante el acto quirúrgico.

Saber escuchar es un arte más complejo que hablar, constituye uno de los mejores recursos que se emplean para enfatizar la atención en aquello que el interlocutor está comunicando. De este modo, el profesional en el área quirúrgica tiene que saber escuchar, si no, puede omitir datos fundamentales al desconocer información acerca del paciente y/o procedimientos, lo que limitará su labor, no logrando ofrecer una intervención óptima al paciente. Al contrario, cuando existe armonía en la información, es decir, que exista comprensión en lo que se dice, la interacción comunicativa será más eficaz ${ }^{(5)}$. Por tanto, todo profesional al informar fehacientemente aquello relacionado con los procedimientos de cirugía, eleva los estándares de seguridad en el paciente quirúrgico, equipo de profesionales y entorno.

Una de las múltiples funciones del profesional de enfermería es reunir el equipo, instrumental y material necesario para los procedimientos quirúrgicos, y así como informar de la carencia de insumos específicos para cada procedimiento quirúrgico, en un ambiente hospitalario, específicamente dentro del quirófano, la enfermera se enfrenta a diversos conflictos en los procedimientos que requieren conocimiento, habilidad e inmediata respuesta a situaciones que le exigen esfuerzo físico y mental, así como su pronta y efectiva intervención en aquellos eventos que se presenten ${ }^{(6)}$, debiendo alertar a las instancias correspondientes sobre las condiciones de la infraestructura que comprometan la seguridad de los pacientes.

Todo lo anterior en función de las responsabilidades éticas y legales que se generan en su ejercicio profesional, para evitar un caso de evento adverso predecible ${ }^{(7)}$. Una previsión constante en la actuación del profesional de enfermería, relacionada con su aptitud para identificar los incidentes y comunicarlos inmediatamente al equipo quirúrgico de tal manera proteger el bienestar del paciente.

Dentro del área quirúrgica, los profesionales de la salud deben estar bien informados acerca de procedimientos y temas entorno al paciente, por ejemplo las alergias; ya que una información deficiente en el equipo multidisciplinario, ocasionara errores durante la cirugía, trátese de regiones quirúrgicas o pacientes ${ }^{(8)}$. Cuando la enfermera le comunica al cirujano -Yo le dije ¡sabe que medico i se cierra la sala,- porque se va serrar?! Porque hay secreción! - una gotita!-, en las clínicas norteamericanas se dice que la salida de secreción purulenta, fétida o no, se considera como pus y está contaminada-, su actuar refleja una actuación positiva en la comunicación,

En 1967, Watzlawick ${ }^{(2)}$ señalaba que la interacción humana es un sistema de comunicación caracterizada por las propiedades de retro-alimentación que son el foco natural para la pragmática de los fenómenos comunicacionales, así, el contexto influye en la interpretación que se dé al acto del habla, si estas características se presentan al interactuar el equipo quirúrgico, el resultado reflejará una comunicación asertiva en beneficio del usuario. 
Si el profesional de enfermería se comunica con el equipo quirúrgico a través de frases confirmatorias antes, durante y después del procedimiento, posibilita a otros profesionales y no sólo a enfermería a dar cumplimiento de las metas internacionales: comunicación efectiva, por tanto, cirugía segura en la institución hospitalaria.

Las enfermeras participantes contextualizan que su intervención parte importante en las acciones del equipo quirúrgico y son quienes deben recibir notificaciones precisas, similares a aquellas que se comunican a los demás. Watzlawick ${ }^{(2)}$ sugiere una relación simétrica en la comunicación entre los profesionales de salud, donde el intercambio de información se lleve a cabo en un plano de igualdad, considerando que pertenecer a un equipo, compromete a participar activamente en todo el proceso a fin de reforzar la comunicación dentro del quirófano.

La inseguridad aumenta durante el procedimiento al omitir información precisa y de gran importancia para un integrante del equipo quirúrgico en cualquier evento, resalta una integración deficiente del mismo; una buena relación influye en toda comunicación, por tanto, no es posible comunicarse de manera efectiva, si el profesional desatiende a su interlocutor ${ }^{(9)}$; en este tenor, un equipo de profesionales interactúa con un objetivo en común: la seguridad del paciente.

Los miembros del equipo tienen que transmitir los problemas con prontitud, proporcionando así tácticas encaminadas a resolver los problemas que emergen en el propio contexto comunicativo(10). Por otra parte, no sólo se trata de conformar un equipo y permanecer en él, sino que la información emitida, esté direccionada a cada uno de los profesionales para que, como equipo, se logre la participación de cada integrante, al generar esa reciprocidad en la comunicación, es la acción que el profesional de enfermería requiere de su equipo quirúrgico.

La interpretación del mensaje depende del acento, de los signos lingüísticos, así como del contexto en el cual tenga lugar una comunicación. Watzlawick menciona que un aspecto conativo se centra en el tipo de mensaje, el cual debe entenderse que es para mejorar la relación entre las personas que se comunican ${ }^{(2)}$. Por esta razón, el profesional de enfermería menciona - a veces no hablamos claro y fuerte esa es causa de confusión (E-4)-, es conveniente hablar en voz alta para que el mensaje sea claro y escuchado por todo el equipo quirúrgico dentro de la sala quirúrgica.

En la comunicación, aparte del tono de voz, se debe emplear un ritmo armonizado, considerando que un volumen demasiado alto condiciona cierto rechazo del receptor; en cambio, demasiado bajo dificulta su comprensión y demuestra inseguridad o temor en el comunicador ${ }^{(11)}$. Los mensajes son positivos cuando la comunicación fluye recíprocamente; de lo contrario, pueden ser confusos; un volumen muy alto en el tono de voces causa de tensión en la sala y, en consecuencia, perturba el sistema comunicacional en cada uno de los profesionales del equipo quirúrgico ${ }^{(6)}$.

Cuando hay interferencia en la comunicación, se presentan diversos factores -como lo describe esta investigación-; el ruido se presenta en todo sistema comunicacional, de manera específica, el ruido psicológico se manifiesta en el equipo quirúrgico a través del estado de ánimo y las emociones negativas que bloquean un proceso racional e impiden que exista empatía en la comunicación entre los profesionales.

De tal manera, toda emoción manifestada en una persona pertenece a un estado cualitativo de orden afectivo, constituye un consenso social, una reacción comportamental; la relación interpersonal es muy característica entre profesionales debido a la convivencia que a diario se da entre el grupo ${ }^{(12)}$. En efecto, el profesional de enfermería debe conducirse de forma natural al expresarse, y regirse racionalmente respecto al control de sus emociones, a fin de entender y comprender al otro; un estado emocional positivo mantiene las buenas relaciones y crea el ambiente propicio para una comunicación que no admita duda en el equipo quirúrgico.

\section{CONSIDERACIONES FINALES}

El factor relacional de toda comunicación influye primordialmente en las personas que interactúan durante un tiempo prolongado, el conocimiento que tiene una persona acerca de otra influye en el estilo de comunicación, por lo tanto, un grupo que convive unido -como en el quirófano-, interactúa 
exitosamente y así garantiza la seguridad del paciente dentro de cada sala quirúrgica.

Las enfermeras infieren que en todo procedimiento es indispensable comunicarse con anticipación y de forma clara y precisa, además de corroborar cualquier imprevisto, pues la falta de algún insumo o instrumento, así como no confirmar la información durante el procedimiento, ocasiona eventos adversos, e incrementa la morbimortalidad del paciente en la sala de cirugía.

El concepto equipo es imprescindible para el profesional de enfermería, pues cada uno de sus miembros debe estar comprometido en colaborar de manera conjunta, en la realización de las funciones correspondientes e involucrándose en toda la información que se presente durante el acto quirúrgico.

El ruido psicológico se manifiesta en las emociones de los integrantes del equipo quirúrgico; en opinión de enfermería se presenta en quien intenta separar el estado emocional entre su vida laboral y personal, pero no puede evitarlo y se manifiesta en su actividad diaria; no obstante, está consciente de moderar sus emociones negativas para no afectar la relación comunicativa que mantiene la seguridad dentro del equipo en el área quirúrgica; interpretándose así la manera de comunicarse.

Cabe resaltar que el estudio abordó principalmente la opinión del profesional de enfermería, siendo necesario estudiar la perspectiva de los otros profesionales del equipo de esta manera ampliar el panorama de la comunicación dentro del área.

\section{REFERÊNCIAS}

1. Flick U. Introducción a la investigación cualitativa. 2da ed. Coruña, España: Morata; 2012.

2. Watzlawick P, Beavin HJ, Jackson D. Teoría de la comunicación humana, Interacciones, patologías y paradojas. Barcelona Espana. Herder; 1981.

3. Minayo MCS. O desafio do conhecimento: pesquisa qualitativa em saúde. 11ª ed. São Paulo: Hucitec; 2008.

4. Moñux YRL, Juan LC, Marcos AP, Soler MLM. Las relaciones interpersonales de los enfermeros en asistencia hospitalaria y el uso de habilidades comunicativas. Texto Contexto Enferm. [Internet] 2014;23(3) [cited 11 dec 2016]. Available from: http://dx.doi.org/10.1590/0104-07072014002010013.

5. Garcia JAS, Ruiz JA, Baños AIC, Lázaro JAM, Ramis BA. La importancia de la escucha activa en la intervención Enfermera. Enfermería Global. [Internet] 2014;13(2) [cited 6 may 2016]. Available from: http://revistas.um.es/ eglobal/article/view/178261/160601.

6. Oviedo AD. Adaptación y estrés laboral en el personal de las unidades médico-quirúrgicas. RISCH. [Internet] 2013;2(3) [cited 9 oct 2016]. Available from: http://www.ricsh.org.mx/index.php/RICSH/article/view/17/31.

7. Laza COU. Competencias de Enfermería para la seguridad del paciente. Rev Cubana de Enferm [Internet] 2011;23(2) [cited 6 may 2016]. Available from: http://www.bvs.sld.cu/revistas/enf/vol27_3_11/enf08311.htm.

8. Wauben LSGL, Doorn CMD, van Wijngaarden JDH, Goossens RHM, Huijsman R, Klein J, et al. Discrepant perceptions of communication, team work and situation awareness among surgical team members. International Journal for Quality in Health Care. [Internet] 2011;23(2) [cited 19 apr 2017]. Available from: http://dx.doi. org/10.1093/intqhc/mzq079.

9. Clayton J, Isaacs AN, Ellender I. Perioperative nurses experiences of communication in a multicultural operating theatre: A qualitative study. Int J Nurs Stud. [Internet] 2016;54(n.esp) [cited 22 jul 2016]. Available from: http:// dx.doi.org/10.1016/j.ijnurstu.2014.02.014.

10. Ortiz LG, López MEA, González MAR. Análisis epistemológico de la comunicación oral del inglés con fines profesionales. MEDISAN. [Internet] 2015;19(3) [cited 15 jan 2017]. Available from: http://scielo.sld.cu/scielo. php?script=sci_arttext $\&$ pid=S1029-30192015000300019.

11. Morante JCG. La gestión de la comunicación en el ámbito sanitario. Revista de Comunicación y Salud. [Internet] 2012;2(1) [cited 22 jul 2016]. Available from: http://revistadecomunicacionysalud.org/index.php/rcys/ 
article/view/29/23.

12. Charaudeau P. Las emociones como efectos de discurso. Versión. [Internet] 2011;(26) [cited 6 may 2016]. Available from: http://www.patrick-charaudeau.com/Las-emociones-como-efectos-de.html. 